\title{
The Danish Physical Society
}

\section{J. Bang and P. Sigmund}

The Danish Physical Society (Dansk Fysisk Selskad, DFS) was established in 1972 as a common organization embracing two existing societies : The Danish Society for Physics and Chemistry of Condensed Matter, and the Association for Physics. Its aim is to promote contact among Danish physicists and to represent Danish physicists in national and international contexts. From 1 January 1973, Denmark's representation in EPS was taken over by the Danish Physical Society. Since the Society is so new it has not yet developed much activity of its own, but a short account of the activities of its member organizations is given below.

The Association for Physics (Fysisk Forening) was started in 1908 by a group of physicists working at the Technical University of Denmark, Copenhagen, with the aim of promoting discussion and exchange of information among Danish physicists. The Technical University, founded by Ørsted, was at that time the only institution in Denmark where physical research was carried out on a large scale. On the first board of the Association, the name Julius Hartmann, an early pioneer of magnetohydrodynamics, is notable. When, in 1921. the Niels Bohr Institute (at that time "Universitetets Institut for Teoretisk

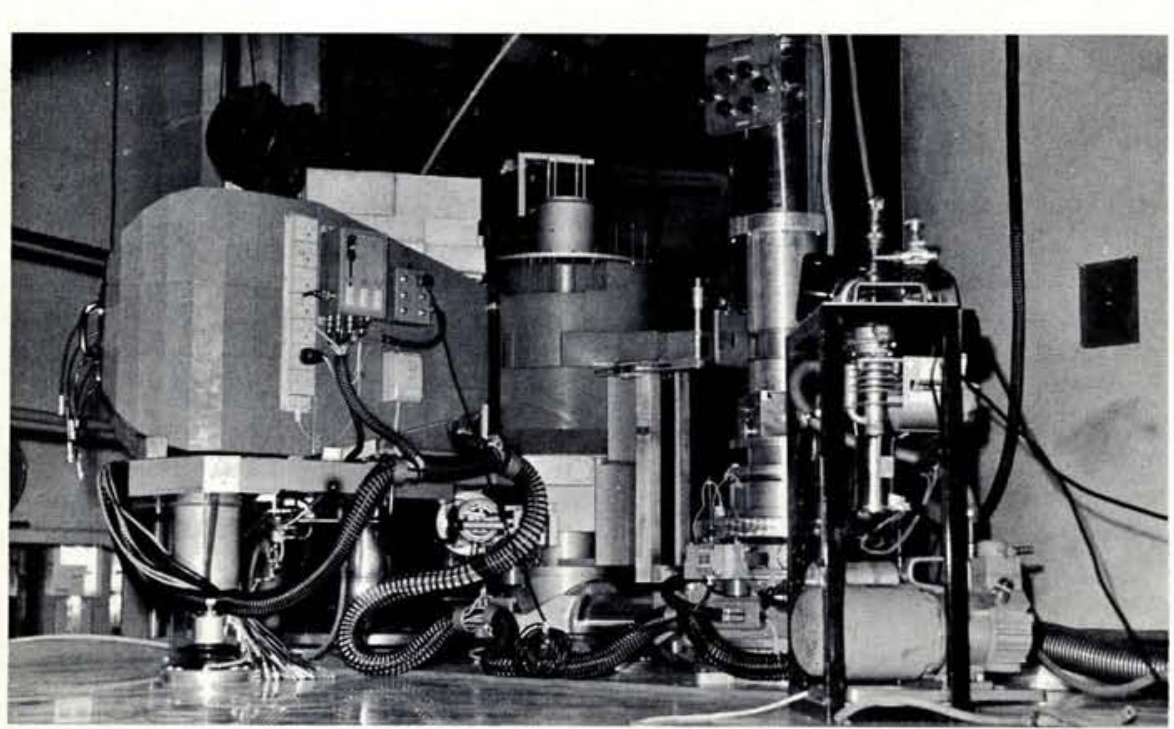

Fig. 2 Triple axis spectrometer at the DR3 reactor, Rise. The instrument is used for the study of inelastic scattering of neutrons from condensed matter. The cross-section depends on the energy and momentum transfer in the scattering process and it is proportional to the spatial and temporal pair correlation function of the scattering particles, e.g. nuclei or unpaired magnetic electrons. This experimental method has been used at Riso for a wide range of problems in solid state physics, e.g. spin waves in the rare earth metals and magnetic insulators, magnetic structures, liquids, phonon dispersion relations, and critical phenomena in alloys and magnetic systems.

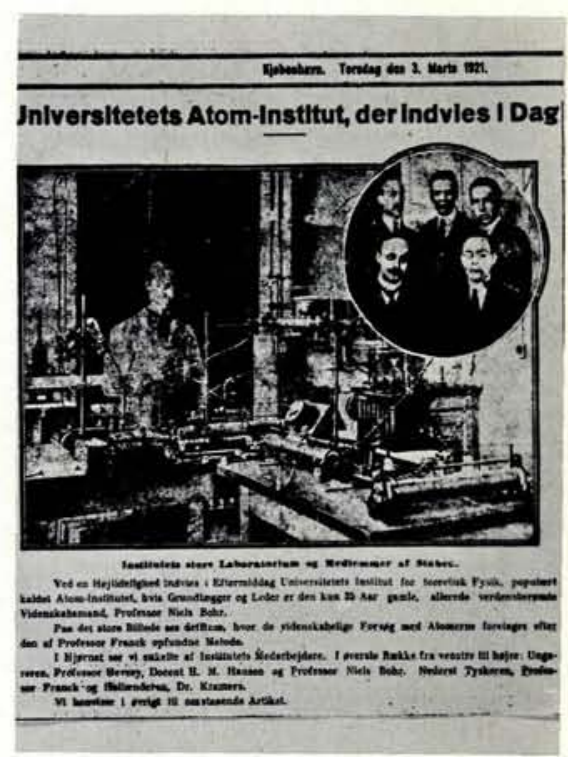

Fig. 1 A newspaper picture from the start of the Niels Bohr Institute in 1921 showing some of its first collaborators.

In the laboratory stands J.C. Jacobsen; in the circle are Hevesy, H.M. Hansen, Niels Bohr, Franck and Kramers.

H.M. Hansen and J.C. Jacobsen, who later became professors at the University of Copenhagen, have also been chairmen of Fysisk Forening.

solid-state scientists in Denmark were organized less formally within the "Study Group for Solid-State Physics and Chemistry ". This group had been formed in 1961 by a number of physicists and chemists with the aim of stimulating a major effort in solidstate research in Denmark. It was felt that in a small country, active contacts to the international scientific community and close cooperation between the interested groups within the country were desirable in order to establish a stimulating research atmosphere in a comparatively new field. With this in mind, monthly or bi-monthly meetings were held at regular intervals at the University of Copenhagen, the University of Århus, the Technical University at Lyngby, and the Research Establishment of the Atomic Energy Commission at Risø. A substantial fraction of the contributions to these meetings were extensive review lectures on broad topics given by guest speakers from abroad. Many of the topics of presentday solid-state research in Denmark were initiated by those lectures.

At present, the society has about 150 members, most of whom are scientists and engineers engaged in pure and applied research, and in development, at the four institutions mentioned above, and at the University of Odense, the Pharmaceutical Institute in Copenhagen, A/S Danfysik, A/S Ferroperm, and other educational and industrial institutions. 


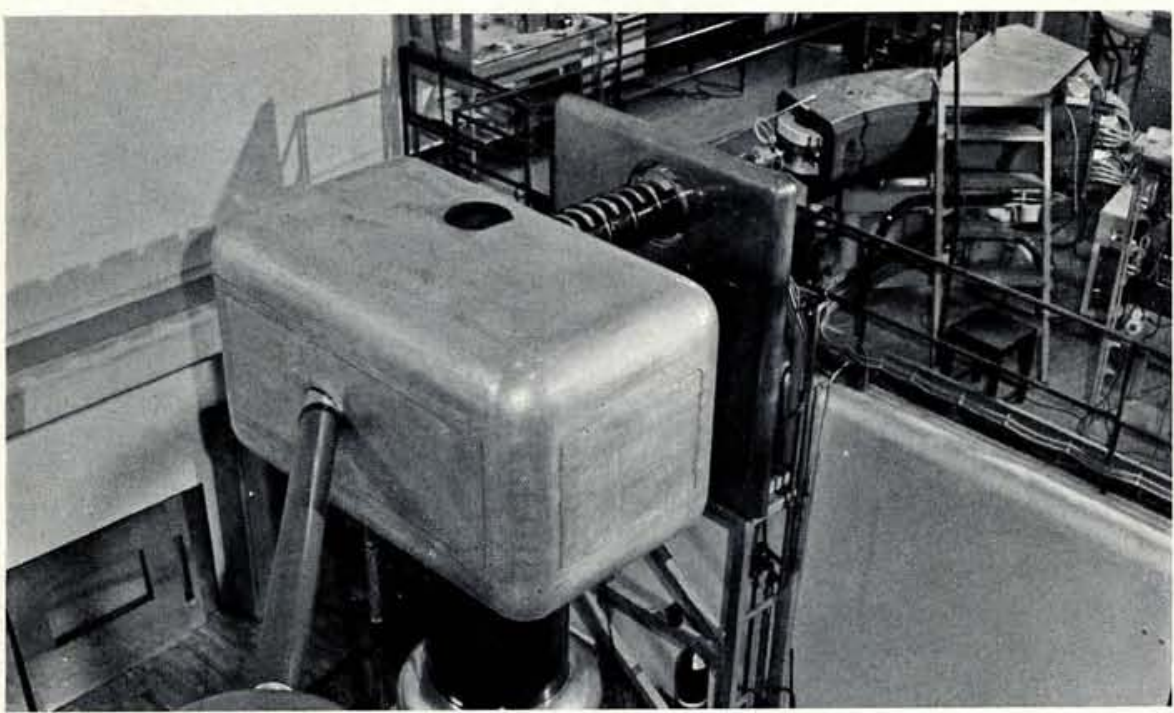

Fif. 3 The $600 \mathrm{kV}$ universal heavy-ion accelerator at the Institute of Physics, University of Århus. Since 1964, when this machine became operational, a substantial amount of the atomic collision studies at the Institute have been performed at this facility. The studies have included channeling and energyloss measurements, beam-foil experiments, and investigations of single and multiple atomic collisions.

The topics covered in the meetings span a wide range of the physics of condensed matter as well as selected topics in atomic physics and spectroscopy, and solid-state chemistry. Already in 1970, shortly after its foundation, the society was attached to the European Physical Society as an Ordinary Member (category 4 b). Many members have applied for Individual
Ordinary Membership in EPS, and a considerable number of individuals have been participating actively in the organization of EPS at various levels.

Address and secretary: P. Lawaetz, Physics Laboratory III, Building 309-C, Technical University of Denmark, Lundtofte, DK-2800 Lyngby

\section{Atomic and Molecular Physics of Ionized Gases \\ Versailies, 3-5 April 1973}

The first Europhysics Study Conference on Atomic and Molecular Physics of lonized Gases was held at Versailles from 3-5 April 1973, and was attended by approximately 100 participants. The Subject of the meeting was the elementary processes in ionized gases, together with the associated macroscopic plasma properties. With a total of 9 invited and 30 contributed papers, the latter being grouped according to subject matter (and some read by title only), ample time was available for discussions and no parallel sessions were necessary.

The Conference got off to an invigorating start with papers by M.A. Biondi and J.N. Bardsley (Experimental and Theoretical Aspects of Electron-ion Recombination), followed by J.L. Delcroix (Metastables). A.B. Phelps (Atomic Physics and Gas Lasers) and H.J. Kunze (Laser Scattering), together with several contribued papers, led to lively discussions. Papers by N.D. Twiddy (Flowing Afterglows), T. Märk (Mass Spectrometric Probing of Gaseous Plasmas) and K. Suchy (Transport Phenomena in ionized Gases) completed what could be described effectively as processes in weakly-ionized plasmas.

In the highly-ionized regime, papers by R.W.P. McWhirter (Spectral Line Intensities of Laboratory Plasmas and Atomic Collision Processes) and J. Richter (Departure from Local Thermodynamic Equilibrium in Arcs) showed the continuing interest in astrophysical and fusion machine plasma.

An 'audience reaction' discussion held towards the end of the conference showed enthusiasm for future meetings of this kind, provided that the number of participants was maintained sufficiently small for meaningful discussions to be possible. It is hoped that regular meetings on this topic, or on more specialized parts of it, will be held under the auspices of EPS.

A special word of thanks is due to the French organizing committee at Sacly - particulary M. Manus and M. Berlande - who not only had put forward the idea of such a meeting but those organization of both the scientific and social programmes left very little to be desired. M.C. Sexton

\section{Theoretical Physics}

\section{An Advanced Text}

by B.G. LEVICH, Institute of Electrochemistry, Academy of Sciences of the U.S.S.R. Moscow.

Translated from the Russian by S. Subotic Belgrade. Translation edited by J. Schneps, Tufts University. Medford, Mass., U.S.A. and A.J. Manuel, Leeds University, England.

This is the first edition of the famous text book of theoretical physics widely used in Russian universities. The work, which is updated and expanded, is published in four volumes. The text is intended as an introduction to theoretical physics and is written in such a way that all material necessary for understanding the later sections is covered earlier in the work.

Just published

Volume IV : Quantum Statistics, Physical Kinetics

1973. about 430 pages

Dfl. 47.00 (about US $\$ 16.50$ )

ISBN 0720402026

Volume 4 covers quantum statistics and the essential concepts of physical kinetics, which are not usually presented in a general course on theoretical physics. The rapid development of physics and the present wide interest in non-equilibrium and non-stationary processes has necessitated the expansion of the section on physical kinetics in this edition.

CONTENTS: Quantum statistics. Physica kinetics. Kinetic theory of gases and gaslike systems. Time correlation function method and Onsager's theory. Solid-state theory. Sudject index.

Already published

Volume I: Theory of the Electromagnetic Field, Theory of Relativity

1970. 415 pages

Dfl. 47.00 (about US $\$ 16.50$ )

Volume II: Statistical Physics, Electromagnetic Processes in Matter

1971. 668 pages

Dfl. 75.00 (about US $\$ 26.30$ )

Volume III : Quantum Mechanics 1973. 642 pages

Dfl. 120.00 (about US $\& 42.10$ )

\section{NORTH \\ P.O. Box 211, Amsterdam, The Netherland}

Sole distributors for the Western Hemisphere Wiley Interscience Division, John Wiley \& Sons Inc., New York. 